\title{
HPV-Subtypisierung mittels Southern-Blot-Technik an
}

\section{Zervixkarzinomen}

\begin{tabular}{|l|l|l|}
\hline J. & & Hosmann \\
\hline K. & & Czerwenka \\
\hline E. & Gitsch \\
\hline
\end{tabular}

I. Universitäts-Frauenklinik (Vorstand: Prof. Dr. E. Gitsch)

Dr. J. Hosmann, I. Universitäts-Frauenklinik, Spitalgasse 23, A-1090 Wien

Die Anwesenheit von HPV-Subtypen 16 und 18 spielt ätiologisch eine bedeutende Rolle bei der Entstehung eines manifesten Zervixkarzinoms. Diese Assoziation wird durch die Beobachtung unterstützt, daß HPV 16 DNA in Metastasen genauso wie im Primärtumor gefunden wird und HPV 18 DNA in Hela Zellen und anderen zervixkarzinomspezifischen Tumorzellinien. Nach L. Gissmann, zeigen sich die HPV Subtypen 16 und 18 in 70\% zervikaler Karzinome, wobei deutlich auf die regionale Unterschiedlichkeit in der Vertei-lung hingewiesen wird.

Im Gegensatz dazu steht die Verteilung von HPV Subtypen bei koilozytotischen Dysplasien und Condylomata acuminata. HPV 6 und 11 finden sich ebenfalls regional unterschiedlich in mehr als $90 \%$ genitaler Warzen. Meist erkennt man kolposkopisch eine kleine flache Läsion, welche sich kaum von einer leichten Dysplasie unterscheiden läßt. Das typische Bild der Koilozytose ergibt zytologisch den Hinweis auf ein virales Geschehen.

HPV 16 und 18 wurde erstmalig an Zervixkarzinomen unter Verwendung der Southern Blot Hybridisation entdeckt. 1974 erfolgte die Transskription von HPV DNA auf Escheria coli durch DNA Polymerasen. Dabei entstand komplementär jene DNA, welche später radioaktiv markiert, als sogenannte „probe” oder „Sonde” für die Identifizierung des

Freie Vorträge

249

Papilloma Virus DNA verwendet wird. Rekombinante DNA Moleküle, mit dem komplet-ten Genom des HPV Virus, können in Plasmiden geklont werden und stehen damit dem Labor in größeren Mengen zur Verfügung.

Bei der von uns dargestellten Technik des Southern Blottings erfolgt zunächst die Isolierung der DNA aus kernhaltigem Material. Die Fragmentierung besorgen Restriktions-enzyme an für sie spezifischen Stellen. Eine anschließende Auftrennung der DNA-Fragmen-te wird in der Gelelektrophorese durchgeführt. Das eigentliche Blotting ist die Ubertragung der DNA-Stücke vom Gel auf Nitrocellulosefilter. Die Identifizierung findet durch die Hybridisation mittels radioaktiv markierter oben erwähnter DNA ,probes” statt. Die eigentliche Sichtbarmachung der spezifischen DNA Abschnitte erfolgt durch Autoradiogra-phie.

Die beschriebene Southern Blot Technik erlaubt eine HPV-Diagnostik mit einer Sensibilität von 0,1 Virus Genom/Zelle, bei einer Unterscheidungsmöglichkeit gegenüber bakteriellen Plasmidsequenzen. Die Sicherheit der Ergebnisse beruht auf der Verwendung eines Homogenisates kernhaltigen Materials von Tumorgewebe bzw. zytologischem Material. Nach weiterer Routineerfahrung mit der beschriebenen Technik erfolgt die Anwendung am 
histologischen Schnitt oder zytologischen Abstrich, wobei mit einer, auch in der Literatur beschriebenen, Unzuverlässigkeit der Ergebnisse zur Zeit noch gerechnet werden muß. Uns war die Bestimmung der HPV Subtypen 6, 11 , 16 und 18 möglich, wobei aus einer Gewebemenge von weniger als $0,1 \mathrm{~g}$ nach etwa 10 Tagen das Ergebnis vorlag.

Auffallend war die hohe Anzahl HPV-positiver Befunde aus unselektioniertem Tumorgewebe eigenen Materials. Von 13 untersuchten Zervixkarzinomen fand sich zehnmal ein für HPV 16, einmal für HPV 18 und einmal für HPV 6 positiver Befund. Bei einer einzigen Patientin konnte kein Virus nachgewiesen werden. Die operative Präparategewin-nung erfolgte durchwegs mit der an unserer Klinik etablierten Radikalmethodik nach Latzko, wobei die histopathologische Stadieneinteilung nach UICC von pTla bis pT2a reichte. Histologisch handelte es sich durchwegs um unverhornte Plattenepithelkarzinome, großzellig und mäßig differenziert, mit massiv ausgeprägten Kernatypien.

Eine Erweiterung des Vortragtitels erfolgte durch die HPV Bestimmung an den Vorstufen möglicher Zervixkarzinome. Zweimal handelte es sich dabei um atypische Kondy-lome mit koilozytotischen Atypien. Eine Patientin war HPV 16 positiv, wobei aufgrund der zusätzlichen mittelgradig bis schwere Dysplasie die Konisation durchgeführt wurde. Auch die dyplastischen Läsionen mit abnormer mitotischen Aktivität ist eine starke Assoziation zu HPV 16 Sequenzen anzutreffen. Sie fehlt meist im koilozytotischen Zellmaterial, welches im Gegensatz dazu HPV 6 oder 11 positiv ist.

Die Analyse der HPV Subtypen mittels Southern Blot Technik erlaubt uns daher am eigenen Gewebe sowie zytologischen Material eine Risikogruppenerfassung mit entspre-chender therapeutischer Konsequenz.

L. Literatur beim Verfasser. 